\title{
Serum uric acid: Association with anthropometric, lipid and complete blood count parameters in Iranian healthy population
}

\section{Hamid Soori}

Shaheed Beheshti University of Medical Sciences

\section{Parinaz Rezapour}

Shaheed Beheshti University of Medical Sciences

\section{Hadis Najafimehr}

Shaheed Beheshti University of Medical Sciences

Toktam Alirezaei ( $\boldsymbol{V}$ alirezaei.toktam@sbmu.ac.ir)

Shaheed Beheshti University of Medical Sciences https://orcid.org/0000-0002-4473-7093

\section{Research article}

Keywords: Complete blood count, lipid profile, anthropometric index, serum uric acid

Posted Date: April 2nd, 2020

DOI: https://doi.org/10.21203/rs.3.rs-20016/v1

License: (c) (i) This work is licensed under a Creative Commons Attribution 4.0 International License. Read Full License 


\section{Abstract}

Objectives A relationship between elevated serum uric acid (SUA) and hypertension, metabolic syndrome and cardiovascular disease has been established. In this study, the relationship of SUA levels and anthropometric measures, serum lipid profile and neutrophil to lymphocyte ratio (NLR) and platelet to lymphocyte ratio (PLR) was examined.

Methods Anthropometric parameters including body-mass index (BMI), waist circumference (WC), waist to height ratio(WHtR), waist to hip ratio(W/H), waist to pelvic ratio(W/P), neck circumference $(N C)$, body fat mass(BFM) were obtained, and serum lipid profile containing, low-density lipoprotein cholesterol (LDLC), high-density lipoprotein cholesterol (HDL-C), total cholesterol, triglycerides(TG), also, NLP, PLR, basal metabolic rate (BMR), visceral fat level (VFL) and percent body fat (PBF) were measured among 2921 healthy subjects of young and middle-aged Iranian people. Statistical analysis was performed using SPSS 21 software. To assess the normality of data, the Kolmogorov-Smirnov test was used. Logarithmic transformation was performed for some variables with non-normal distribution. The association between 2 quantitative variables was measured using bivariate correlation (Pearson or Spearman). Pearson correlations and multiple regression analysis were performed to assess the correlation between variables. Simple and multiple regression analyses were performed to predict some variables. P-value $<0.05$ was considered significant.

Results There were 1113 males (mean age, $41.49 \pm 8.62$ years) and 1808 females (mean age, $42.36 \pm$ 9.07 years) in this study. the male group had a mean SUA level of $4.81 \pm 1.2 \mathrm{mg} / \mathrm{dl}$ and the female group had a mean of $4.76 \pm 1.1 \mathrm{mg} / \mathrm{dl}$. The results of data analysis showed all studied factors were correlated with SUA level except VFL, BFM, and PLR. The highest correlation was related to skinfold fat thickness, BMR and HDL.

Conclusion According to the finding of this study, SUA level measurement might be advisable in healthy population to identify those at increased risk of health problems who might benefit from further evaluation.

\section{Introduction}

SUA is produced by metabolism of purine nucleotides, it is one of the major hydrophilic antioxidant in human blood plasma and inhibits free radicals, so, there were some theories that increased SUA levels would be good based on antioxidant activities $[1,2,3,4,5]$.

On the other hand, SUA increase correlates and predicts development of conditions associated with oxidative stress. [6] Various studies have shown the relationship between elevated SUA levels and an increased risk of hypertension, metabolic syndrome, obesity and renal disease [7-14].

Moreover, recent evidence has suggested that UA is an inflammatory factor, which can induce endothelial dysfunction and elevated SUA can be considered as a cardiovascular risk factor, therefore, SUA has been 
lionized as a cardiovascular risk factor in recent prospective and cohort studies $[15,16]$.

The contribution of dyslipidemia and disturbed anthropometric indices to cardiovascular risk are well established [17-19]. BMI and central adiposity have been identified as potential risk factors of major metabolic problems. In several studies on metabolic syndrome have reported that SUA is related to BMI, WC, and dyslipidemia $[16,20,21]$.

NLR and PLR are novel inflammatory markers and associated with worse results in various disease states [22].

The purpose of this study was to evaluate the overall of SUA level in young and middle age healthy population and to explore the association between SUA and anthropometric indices, serum lipid profile, NLR and PLR

\section{Method}

\section{Participants}

This cross sectional study is a pilot study of a health care employee's prospective cohort study among staff at Shahid Beheshti University of Medical Sciences in Tehran, Iran, which was initiated in October 2017 [23].

In this study, there are 3256 employees who participate from 2017 to 2019. The documents are collected using self-report data, interview, clinical and laboratory findings.

The examinations include to complete a health and medical history questionnaire, taking a blood sample and measurement of anthropometric parameters. Eligibility criteria included age $18-65$ years, voluntarily participation, and related medical history. Patients with a history of disease including diabetes mellitus, hypertension, heart disease, hepatic, kidney, gastrointestinal, hematological and respiratory disease,

cancer and stroke were excluded from this study. Ultimately, in total 2921 subjects were enrolled in this study. The participants were divided to 3 groups based on their BMI $(\mathrm{Kg} / \mathrm{m} 2)$. Normal group 18.5= $<$ BMl<24.9, over weight:25=<BMl<29.9, and obese group: $B M I \geq 30$.

Participants were informed about the study by written informed consent. The confidentiality of participants' information was respected.

\section{Data collection}

Complete cell count, fasting sugar, lipids (including total cholesterol, HDL, LDL-C, triglyceride), aspartate aminotransferase (AST), alanine aminotransferase (ALT), blood urine nitrogen (BUN), serum uric acid, creatinine $(\mathrm{Cr})$, and routine examination of the urine were measured after fasting for at least 12 hours. The blood samples were examined within 4 hours of collection. 
Anthropometric parameters including height, weight, BMI, arm circumference (AC), wrist circumference, hip circumference $(\mathrm{HC})$, pelvic circumference $(\mathrm{PC}), \mathrm{WC}, \mathrm{NC}, \mathrm{W} / \mathrm{H}$ and $\mathrm{W} / \mathrm{P}$ were measured using the InBody 770 analyzer.

The triceps skinfold site was used for the assessment of skinfold fat thickness using caliper device.

Nursing staffs educated for the survey measured anthropometry and supervised by a trained doctor. Height was measured with a fixed standard stadia meter following study protocols without shoes and weight was assessed in light clothing. BMI was computed as weight $(\mathrm{kg})$ divided by height in meters squared $\left(\mathrm{m}^{2}\right)$.

\section{Statistical analysis}

Data analyzing was done using SPSS 21 software (Version 18.0; SPSS Inc. Chicago, IL, USA). For descriptive statistics of qualitative variables, number and percent, and for describing quantitative variables, mean and standard deviation (SD) were used. Mann- Whitney test was used for comparing continuous variable with non- normal distribution. Chi- square test was done for evaluating association between categorical variables. For assessing correlation between non-normal distributed continuous variable, Spearman's test was used. Simple and multiple regression analyses were performed to predict some variables.

\section{Results}

A total of 2921 employees were participated in study. Among all participants, $1113(38.1 \%)$ were male and $1808(61.9 \%)$ were female. The mean age of female and male was $42.36 \pm 9.07$ and $41.49 \pm 8.62$ years, respectively. There was a significant difference for age between male and female ( $P$ - value $=0.02)$ and the median age for both gender was 42 years.

Most participants had bachelor degree (36\%) also education level between male and female was different ( $P$-value $<0.001)$. The number of subjects with collegiate education was $1990(72.5 \%)$ and subjects without collegiate was 754 (27.5\%). The BMI for all participants was $27.03 \pm 4.33 \mathrm{Kg} / \mathrm{m} 2$ and there was not any difference for both gender $(P$ - value $=0.63)$. The participants were evaluated for laboratory and anthropometric components and also were compared for both gender.

Details of comparison are presented in table 1. Most of parameters were the same for male and female and only were different in some items. In the male, cholesterol (182.28), LDL (102.45) and platelet (264.68) counts were higher than female (P-value <0.001). In the female, HCT (42.65) and RBC (5.07) were higher than male $(P$-value $<0.001)$. In the case of anthropometric parameters, height of male (160.43) was higher than female (157.51) $(P$-value= 0.01). For male, $\mathrm{HC}(P$-value $=0.01)$ and skinfold fat thickness was higher than female $(P$-value $<0.001)($ Table 1$)$.

\section{Discussion}


In this cohort-based study, we observed that all studied factors except VFL, BFM and PLR were correlated with SUA level, although NLR and total cholesterol were correlated only in female subjects and the highest correlation was related to BMR, skinfold fat thickness and HDL. Strengths of the current study was its focus on healthy population without any known medical diseases, that was based on the patient's view of their condition, physical exams and laboratory tests.

Hyperuricemia is associated with cardiovascular disease, but it is commonly assumed a marker of organ dysfunction rather than a pathogenic role for progression and prognosis. SUA is produced by endogenous and exogenous metabolism of urine in human [1]. Although UA is a hydro-philic antioxidant agent, the correlation between SUA levels and various diseases is considered [2-4]. Due to this controversy, UA was no longer regarded as a real cardiovascular risk factor [24]. In the recent years with improved knowledge about the function of UA in cardiorenal disease, discussion about the role of UA has increased.

Recent evidence has proposed that UA is not only an inflammatory marker but also is a direct cause of cardiovascular disease development through atherogenic effect. However, these results come from limited information and still there is the lack of sufficient knowledge of UA function.Several studies have been examined the association of SUA and the risk for hypertension, type 2 diabetes and metabolic syndrome in different population but studies in healthy adults are little [5,25,26].

In recent years, the prevalence of hyperuricemia has been increased in the world population, especially in the developing countries [27-29].

Obesity is known as strong risk factor and independent predictor for the development of hyperuricemia. $[30,31]$ Obesity is a well-established risk factor for cardiometabolic disorders, and its prevalence in adults appears to have increased in recent times [32,33]. Anthropometry is simple, inexpensive and effective method for screening of obesity and metabolic disorders [34]. The most useful anthropometric index of obesity that associates strongly with cardiometabolic disorders remains controversial. BMI is promulgated by the World Health Organization as the most useful epidemiological measure of overall obesity, but it is not suitable to account for body fat distribution [35]. In recent years, various new anthropometric indices have described to evaluate obesity and fat distribution in humans. BMI is a useful marker of body fat based on measurement of weight and height, while WC, WHtR and W/H reflect abdominal or central visceral fat [36-39].

In our study, based on BMI categories, 45.2\% of the patients were overweight (BMI: 25-29.9) and 22.8\% were obese (BMI $\geq 30)$. (Table 1$)$ WHtR $\geq 0.5$ is a simple marker of central (visceral) obesity and in our study mean of WHtR was $0.56 \pm 0.06$.

Several studies have demonstrated association between SUA levels and body weight and positive correlation between SUA level and BMI in healthy subjects, which was also noted in this study. [40-42] Based on some studies, correlation between WC and SUA is higher than BMI. $[43,44]$ In our study, as 
presented in table 2, in addition to BMI, WC and WHtR have positive correlation with SUA level, also, the higher BMI patients had higher mean SUA levels.

In previous studies, NC was found as an indicator of upper body obesity that can be used to determine overweight and obese individuals and is correlated positively with the markers of the metabolic syndrome, insulin resistance and high risk of type 2 diabetes. $[45,46]$ Three cross-sectional studies evaluated the association between NC and SUA level [47-49]. Of note, these all studies were conducted among Chinese adults. Jiang et al reported that NC had positive association with UA level in hyperuricemia and non-hyperuricemia population. [47] The other two studies found NC was significantly associated with likelihood of having hyperuricemia when comparing the highest NC quartile group with the lowest NC quartile group. [48,49] In our study, NC had positive correlation with SUA level, that was compatible with previous studies results. These findings suggest that upper body fat, as estimated by NC, may have a unique association with SUA level even in normal BMI groups.

Bosy-Westphal et al showed that the measurement of BFM as a direct measure of adiposity in comparison with $\mathrm{BMI}$ and $\mathrm{WC}$ had no further advantage to predict of obesity-related metabolic risk [50]. The VFL is a simple method that correlates with the fat mass. [51] In our study, BFM and VFL were not correlated with SUA level in both genders. These findings may suggest that central adiposity markers have closer associations with SUA level than markers of general adiposity.

Basal metabolic rate is dependent to physical exercise and appropriate dietary behavior [52]. The results of this study showed that BMR had a high negative correlation with SUA level in both genders. Similar to this one was found for skinfold fat thickness.

In present investigation, hyperuricemia was explained if participants have SUA levels more than 7.0 $\mathrm{mg} / \mathrm{dL}$ in men or more than $6.0 \mathrm{mg} / \mathrm{dL}$ in women $[53,54]$. Based on this definition, all men participants were nonhyperuricemic and the prevalence of hyperuricemia in women was $18.1 \%$ that was nearly matched with the universal prevalence rate reported to be between $2.6 \%$ and $36 \%$ [55].

We further divided subjects into male and female groups. The male group had a mean SUA level of 4.81 $\mathrm{mg} / \mathrm{dl}$ (SD: $1.28 \mathrm{mg} / \mathrm{dl}$ ), and the female group had a mean of $4.76 \mathrm{mg} / \mathrm{dl}$ (SD: $1.19 \mathrm{mg} / \mathrm{dl}$ ). It is observed that serum UA levels were similar in males and females. Although this result was not accordance with previous studies $[56,57]$. it was anticipated that SUA level in man be more than females, because estrogen promotes excretion of UA [58,59].

Atherogenic dyslipidemia, include high LDL-C and TG levels with low HDL-C levels and anthropometric parameters, such as obesity are modifiable risks in both genders. The contribution of atherogenic dyslipidemia and disturbed anthropometric indices to cardiovascular risk are well established based on many epidemiological studies [17-19].

Hyperuricemia is suggested to play a role in adipose tissue as a mediator of proinflammatory endocrine unbalance which may have an important role in inflammatory process and dyslipidemia that leads to 
atherogenesis [60]. A few investigations described the association between SUA level and lipid profiles [61-63].

Based on our findings, SUA levels were positively correlated with serum TG and LDL-C level, also there was an inverse correlation between SUA and HDL-C level in both genders. Correlation between total cholesterol and SUA level was found only in female. These findings are in line with previous studies $[61,63,64]$. Lin et al reported among components of the metabolic syndrome, abnormal TG had the maximum effect on SUA level [65]. However, the mechanism of the association of TG and SUA level has not been clear whether genetic factors or other factors such as the patient lifestyle are influencing. [66-68] In our study, based on linear regression model, the severity of correlation of TG and LDL was similar.

Moreover, uric acid is known as an inflammatory marker [15]. Whole blood count is an usual clinical test that components of it including neutrophils and lymphocytes are immune system elements which have important roles in inflammatory process. Ratios between these immune system factors (NLR and PLR) have been recorded as inflammatory markers that have been used more often in recent years $[69,70]$.

Many studies have reported the correlation between NLR and disease activity or the relationship with other inflammatory markers in patients with primary Sjögren's syndrome, rheumatoid arthritis, ankylosing spondylitis, and familial Mediterranean fever [71-74]. These studies have been performed mainly in inflammatory diseases, but, the association between SUA level and these novel inflammatory markers is not well investigated in healthy population. The present paper is one of the first studies that performed to evaluate NLR and PLR values in healthy population, and investigating the correlation between those values and UA level. In this study, NLR and PLR values were similar between men and women. NLR value was correlated with SUA level $(P<0.001)$ but no correlation was found between PLR and UA level. So, in healthy population, high UA level may act as an inflammatory marker.

Regarding prevention of disease is prior to treatment and prevention is impossible without a knowledge of the relative causes of disease, this study focused on young and middle-aged healthy people without evidence of any disease, also, in addition to lipid and traditional anthropometric indices, additional novel anthropometric measures and new inflammatory markers were considered.

This study had some limitations. First, the participants were drawn from a particular employee group. This may not be a true representation of general population, therefore, there are limits for application of our results to other populations. Further studies are required to replicate our results in other groups. Second, the cross-sectional study design cannot demonstrate cause-effect relationships between studied factors and SUA.

\section{Conclusion}

Our findings showed SUA level to be correlated with anthropometric indices, lipid parameters and NLR in healthy population. whereas, the data of the role of SUA level and its use in healthy subjects is limited, the 
results of this study suggest that SUA can be used as a marker to trigger the screening for underlying factors of disease occurrence in healthy adults.

\section{Declarations}

\section{Ethical Approval and Consent to participate}

Data collection in this study was approved by the Ethics Commission of Shahid Beheshti University of Medical Science. The patients included in this study provided signed informed consent.

\section{Consent for publication}

No images, videos or other personal data of the participants are included in this manuscript.

\section{Availability of data and materials}

All available data are included in the manuscript. Raw data are not for public use because personal data are included.

\section{Competing interests}

The authors declare that they have no competing interests.

\section{Funding}

Not applicable.

\section{Author's contributions}

TA: analyzed data, drafted, did background research, and revised the manuscript, HS: data collection and revised the manuscript, PR: data collection and drafted manuscript, $\mathrm{HN}$ : analyzed data and drafted manuscript.

\section{References}

1. Choi H.K, Mount D.B, Reginato A.M; American College of Physicians; American Physiological Society, Pathogenesis of gout. Ann Intern Med, 2005. 143: 499-516.

2. Sautin YY, Johnson RJ: Uric acid: the oxidant-antioxidant paradox.Nucleosides Nucleotides Nucleic Acids 2008, 27:608-619.

3. Hooper DC, Spitsin S, Kean RB, Champion JM, Dickson GM, Chaudhry I, Koprowski H: Uric acid, a natural scavenger of peroxynitrite, inexperimental allergic encephalomyelitis and multiple sclerosis. Proc NatlAcadSci U S A.1998; 95:675-680. 
4. Wayner DD, Burton GW, Ingold KU, Barclay LR, Locke SJ. The relative contributions of vitamin E, urate, ascorbate and proteins to the totalperoxyl radical-trapping antioxidant activity of human blood plasma. BiochimBiophysActa. 1987; 924:408-419.

5. ChiouW.K, HuangD.H, Wang M.H,Lee Y.Jand Lin J.D. Significance and association of serum uric acid levels with components of metabolic syndrome in the elderly.ArchGerontolGeriatr. 2012; 55(3): 724-8.

6. Sautin YY, Johnson RJ. Uric acid: the oxidant-antioxidant paradox. Nucleosides, Nucleotides, and Nucleic Acids. 2008; 27(6-7): 608-619.

7. You L, Liu A, Wuyun G, Wu H and Wang P, Prevalence of hyperuricemia and the relationship between serum uric acid and metabolic syndrome in the Asian Mongolian area. J AtherosclerThromb. 2014; 21(4): 355-65.

8. Nagahama K, Inoue T, Kohagura K, Kinjo K and Ohya Y. Associations between serum uric acid levels and the incidence of hypertension and metabolic syndrome: a 4-year follow-up study of a large screened cohort in Okinawa, Japan. Hypertens Res.2014; 38: 213-218.

9. Liu PJ, Ma F, Lou HP, Zhu YN and ChenY. Relationshipbetween serum uric acid levels and metabolic syndromein Chinese postmenopausal women. Climacteric. 2014; 17(2):148-54.

10. Grayson PC, Kim SY, Lavalley M, Choi HK. Hyperuricemia and incident hypertension: a systematic review and meta-analysis. Arthritis Care Res (Hoboken). 2011; 63:102-10.

11.

Kodama S, Saito K, Yachi Y, Asumi M, Sugawara A, Totsuka K, et al. Association between serum uric acid and development of type 2 diabetes. Diabetes Care. 2009; 32:1737-42.

12. Kim SY, Guevara JP, Kim KM, Choi HK, Heitjan DF, Albert DA. Hyperuricemia and risk of stroke: a systematic review and meta-analysis. Arthritis Rheum. 2009; 61:885-92.

13. Wheeler JG, Juzwishin KD, Eiriksdottir G, Gudnason V, Danesh J. Serum uric acid and coronary heart disease in 9,458 incident cases and 155,084 controls: prospective study and meta-analysis. PLoS Med. 2005;2: e76.

14. Kang DH, Nakagawa T, Feng L, Watanabe S, Han L, Mazzali M, et al. A role for uric acid in the progression of renal disease. J Am SocNephrol. 2002; 13:2888-97.

15. Sautin YY, Nakagawa T, Zharikov S, Johnson RJ. Adverse effects of the classic antioxidant uric acid in adipocytes: NADPH oxidase-mediated oxidative/nitrosative stress. Am J Physiol Cell Physiol. 2007;293: 584-96.

16. Rakic MT, Valkenburg HA, Davidson RT, Engels JP, Mikkelsen WM, Neel JV, et al. Observations on the natural history of hyperuricemia and gout. I. An eighteen-year follow-up of nineteen gouty families. Am J Med. 1964; 37:862-71.

17. Libby P. Pathophysiology of Coronary Artery Disease. Circulation.2005; 111 (25): 3481-3488.

18. Manninen V, Tenkanen L, Koskinen P, Huttunen JK, et al. Joint effectsof serum triglyceride and LDL cholesterol and HDL cholesterol concentrationson coronary heart disease risk in the Helsinki Heart Study. Implications for treatment. Circulation. 1992; 85 (1): 37-45. 
19. Kahn HS, Imperatore G, Cheng Y. A population-based comparison of BMI percentiles and waist-toheight ratio for identifying cardiovascular risk in youth. Journal of Pediatrics 2005; 146:482-8.

20. Kuriyama S, Nakano T, Maruyama Y,Sugano N, Takane K, Suetsugu Y, et al. Relationship between serum uric acid levels and muscle strength/volume: a new insight from a large-scale survey. Nihon Jinzo Gakkai Shi. 2014; 56(8): 1260-9.

21. Qin L, Yang Z, Gu H, Lu S, Shi Q,Xing Y, et al. Association between serum uric acid levels and cardiovascular disease in middle-aged and elderly Chinese individuals. BMC CardiovascDisord. 2014; 14: 26.

22. Tamhane UU, Aneja S, Montgomery D, et al. Association betweenadmission neutrophil to lymphocyte ratio and outcomes in patientswith acute coronary syndrome. Am J Cardiol.2008; 102:653-7.

23. Soori $H$, Alipour A, Akbari ME, Argani H, Asadpour Piranfar M, Asadzadeh Aghdaei HR, et al. A review on Health Cohort Study of Employees in Shahid Beheshti University of Medical Sciences (SBMU Cohort). Pejouhandeh 2017;21(6):346-355.

24. Culleton BF. Uric acid and cardiovascular disease: a renal-cardiac relationship? CurrOpinNephrolHypertens. 2001; 10:371-5.

25. Ishizaka N, Ishizaka Y, Toda E, Nagai R, Yamakado M. Association between serum uric acid, metabolic syndrome, and carotid atherosclerosis in Japanes individuals. Arteriosclerosis thrombosis and Vascular Biology 2005; 25: 1038-1044.

26. Dai X, Yuan J,Yao P, Yang B, Gui L, Zhang X, Associationbetween serum uric acid and the metabolic syndrome among a middle- and old-age Chinese population. Eur J Epidemiol, 2013. 28(8): 669-76.

27. Conen D, Wietlisbach V, Bovet P,Shamlaye C, Riesen W, Paccaud F, Burnier M, Prevalence of hyperuricemia and relation of serum uric acid with cardiovascular risk factors in a developing country. BMC Public Health. 2004; 25(4):9.

28. GulabKanwar and Rahul Kabra. Serum uric acid level and obesity: An association. International Journal of healthcare Sciences. 2016; 4(1):52-55

29. Chen L, Zhu W, Chen Z, Dai H, Ren J, Chen J, et al. Relationship between hyperuricemia and metabolic syndrome. J Zhejiang UnivSci B. 2007; 8:593.

30. Ogura T, Matsuura K, Matsumoto Y, Mimura Y, Kishida M, Otsuka F, et al. Recent trends of hyperuricemia and obesity in Japanese male adolescents, 1991 through 2002. Metabolism. 2004; 53(4):448-53.

31. Choi HK, Atkinson K, Karlson EW, CurhanG.Obesity, weight change, hypertension, diuretic use, and risk of gout in men:the health professionals follow-up study. Arch intern Med. 2005; 165,742-8.

32. Poirier P, Giles TD, Bray GA, Hong Y, Stern JS, Pi-Sunyer FX et al. Obesity and cardiovascular diseas: pathophysiology, evaluation, and effect of weight loss: an update of the 1997 American Heart Association Scientific Statement on Obesity and Heart Disease from the Obesity Committee of the Council on Nutrition, Physical Activity, and Metabolism. Circulation 2006; 113: 898-918. 
33. Eckel RH, Kahn R, Robertson RM, Rizza RA. Preventing cardiovascular disease and diabetes: a call to action from the American Diabetes Association and the American Heart Association. Circulation 2006; 113:2943-2946.

34. Lee ZB, Kim ZY. A comparison of the predictive power of anthropometric indices for hypertensive and hypotension risk. PLOS One 2014; 9(1): 1-11.

35. Kashyap K. Comparative evaluation and correlation of different anthropometric indices with blood pressure in adult populations. Int J Basic ApplPhysiol2012; 1(1): 36-41.

36. Baumgartner RN, Heymsfield SB, Roche AF. Human body composition and the epidemiology of chronic disease. ObesRes . 1995; 3 :73-95.

37. Conway JM, Chanesta FF, Wang P. Intraabdominal adipose tissue and anthropometric surrogates in African American women with upper- and lower-body obesity. Am J ClinNutr 1997; 66: $1345 \pm 1354$.

38. Pouliot SC, Despres JP, Lemieux S, Moorjani S, Bouchard C, Tremblay A, Nadeau A, Lupien PJ. Waist circumference and abdominal sagittal diameter: best simple anthropometric indexes of abdominal visceral adipose tissue accumulation and related cardiovascular risk in men and women. Am J Cardiol1994; $73: 460 \pm 468$.

39. Taylor RW, Keil D, Gold EJ, Williams SM, Goulding A. Body mass index, waist girth, and regional adiposity in women: evaluation using receiver operating characteristic curves. Am J ClinNutr1998; 67: $44 \pm 49$.

40. Masuo K, Kawaguchi H, Mikami H, Ogihara T, Tuck ML. Serum uric acid and plasma norepinephrine concentrations predict subsequent weight gain and blood pressure elevation. Hypertension. 2003; 42 : 474-480.

41. Charlotte A, Peter W, Bente B, Kober L, Fosbol EL, Sharma AM, Finer N, Caterson ID, Rode RA, James $\mathrm{PT}$, Trop-Pedersen $\mathrm{C}$. Differential change in serum uric acid concentrations in sibutramine promoted weight loss in diabetes: results from four weeks of the lead-in period of the SCOUT trial. Nutr Metab (Lond). 2009; $6: 42$.

42. WANG H, WANG L, XIE R, et all. Association of Serum Uric Acid with Body Mass Index: A CrossSectional Study from Jiangsu Province, China. Iranian j Public Health. 2014 Nov; 43(11): 1503-1509.

43. Mukhopadhyay P, Ghosh S, Pandit K, Chatterjee P, Maghi B, ChowdhuyS.Uric Acid and Its Correlation with Various Metabolic Parameters:A Population Based Study.Indian J EndocrinolMetab. 2019;23(1):134-139.

44. Hirschler V, Esteban M, Gonzalez C, Molinari C, Castano L. Association Between Waist Circumference and Magnesium and Uric Acid in Indigenous Argentinean Children Living at High Altitude. CardiovascHematol Agents Med Chem. 2016; 14:134-40.

45. Ben-Noun L, Sohar E, Laor A. Neck circumference as a simple screening measure for identifying overweight and obesity patients. Obes Res. 2001; 9:470-477. 
46. Ben-Noun L, Laor A. Relationship of Neck Circumference to Cardiovascular Risk Factors. Obes Res. 2012; 11(2)

47. Jiang J, Cui J, Yang X, Wang A, Mu y, Dong L, Wang S, Gaisano H, Dou J, He Y. Neck Circumference, a Novel indicator for hyperuricemia. Front Physiol.2017; 8:965.

48. Liu YF, Chang ST, Lin WS, Hsu JT, Chung CM, Chang JJ, Hung KC, Chen KH, Chang CW, Chen FC, Shih YW, Chu CM. Neck circumference as a predictive indicator of CKD for high cardiovascular risk patients. Biomed Res Int 2015:745410.

49. Shen X, Wu S, Xu S, Wu Y, Li Y Cui I, Shu R, Gao X. Neck circumference is associated with hyperuricemia: a cross-sectional study. ClinRheumatol . 2019; 38:2373-2381.

50. Bosy-Westphal A, Geisler C, Onur S, Korth O, Selberg O, Schrezenmeir J, Mu“ller MJ. Value of body fat mass vs anthropometric obesity indices in the assessment of metabolic risk factors. Int $\mathrm{J}$ Obes 2006; 30, 475-483.

51. Kurniawan L, Bahrun U, Hatta M, Arif M. Body mass, total body fat percentage, and visceral fat level predict insulin resistance better than waist circumference and body mass index in healthy young male adults in Indonesia. J Clin Med. 2018; 7(5): 96.

52. Sato Y. Practical aspects of exercise therapy for obesity.Pediatric healthcare. JMAJ. 2005; 48(2): 5963.

53. Sui X, Church TS, Meriwether RA, Lobelo F, Blair SN. Uric acid and the development of metabolic syndrome in women and men. Metabolism. 2008; 57(6):845-52.

54. You L, Liu A, Wuyun G, Wu H, Wang P. Prevalence of hyperuricemia and the relationship between serum uric acid and metabolic syndrome in the Asian Mongolian area. J AtherosclerThromb. 2014; $21(4): 355-65$.

55. Uaratanawong S, Suraamornkul S, Angkeaw S, Uaratanawong R. Prevalence of hyperuricemia in Bangkok population. ClinRheumatol. 2011; 30(7):887-93.

56. Duan Y, Liang W, Zhu L, Zhang T, Wang L, Nie Z, et al. Association between serum uric acid levels and obesity among university students (China). Nutr Hosp. 2015; 31(6):2407-11.

57. Bindler RC, Daratha KB, Bindler RJ, Short R. Serum uric acid: relationships with biomarkers in adolescents and changes over 1 year. J PediatrEndocrinolMetab. 2014; 27(5-6):467-73.

58. Sumino H, Ichikawa S, Kanda T, Nakamura T, Sakamaki T. Reduction of serum uric acid by hormone replacement therapy in postmenopausal women with hyperuricaemia. Lancet. 1999; 354:650.

59. Anton FM, Garcia Puig J, Ramos T, Gonzalez P, Ordas J. Sex differences in uric acid metabolism in adults: evidence for a lack of influence of estradiol-17 beta (E2) on the renal handling of urate. Metabolism 1986; 35:343-8.

60. Baldwin W, McRae S, Marek G, Wymer D, Pannu V, Baylis C, et al. Hyperuricemia as a mediator of the proinflammatory endocrine imbalance in the adipose tissue in a murine model of the metabolic syndrome. Diabetes. 2011:DB_100916. 
61. Lippi G, Montagnana M, Luca Salvagno G, Targher G, Cesare GG. Epidemiological association between uric acid concentration in plasma, lipoprotein (a), and the traditional lipid profile. ClinCardiol. 2010; 33: 76-80.

62. Sarmah D, Sharma B. A correlative study of uric acid with lipid profile. Asian Journal of Medical Sciences. 2013; $4: 8-14$.

63. Peng T-C, Wang C-C, Kao T-W, Chan JY-H, Yang Y-H, Chang Y-W, et al. Relationship between hyperuricemia and lipid profiles in US adults. Biomed Res Int 2015;2015.

64. Conen D, Wietlisbach V, Bovet P, Shamlaye C, Riesen W, Paccaud F, et al. Prevalence of hyperuricemia and relation of serum uric acid with cardiovascular risk factors in a developing country. BMC Public Health. 2004; 4 :9.

65. Lin SD, Tsai DH, Hsu SR. Association Between Serum Uric Acid Level and Components of the Metabolic Syndrome.J Chin Med Assoc; 2006;69(11)

66. Ferns GA, Lanham J, Dieppe P, Galton DJ. A DNA polymorphism of an apoprotein gene associated with the hypertriglyceridaemiaof primary gout. Hum Genet 1988; 78:55-9.

67. Moriwaki Y, Yamamoto T, Takahashi S, Tsutsumi Z,Higashino K. Apolipoprotein E phenotypes in patients with gout: relation with hypertriglyceridaemia. Ann Rheum Dis. 1995; 54: 351-354.

68. Lai SW, Ng KC. Which anthropometric indices best predict metabolic disorders in Taiwan? South Med J 2004; 97:578-82.

69. Kumar V, Sharma A. Neutrophils: Cinderella of innate immune system. IntImmunopharmacol2010; 10:1325-1334.

70. Parihar A, Eubank TD, Doseff Al. Monocytes and macrophages regulate immunity through dynamic networks of survival and cell death. J Innate Immun. 2010;2: 204-15.

71. Hu ZD, Sun Y, Guo J, Huang YL, Qin BD, Gao Q, Qin Q, Deng AM, Zhong RQ. Red blood cell distribution width and neutrophil/lymphocyte ratio are positively correlated with disease activity in primary Sjögren's syndrome. ClinBiochem. 2014; 47:287-290.

72. Uslu AU, Küçük A, Şahin A, Ugan Y, Yılmaz R, Güngör T, Bağcacı S, Küçükşen S. Two New Inflammatory Markers Associated with Disease Activity Score-28 in Patients with rheumatoid arthritis: neutrophil-lymphocyte ratio and platelet-lymphocyte ratio. Int J Rheum Dis. 2015; 21.

73. Gökmen F, Akbal A, Reşorlu H, Gökmen E, Güven M, Aras AB, Erbağ G, Kömürcü E, Akbal E, Coşar M. Neutrophil-Lymphocyte Ratio Connected to Treatment Options and Inflammation Markers of Ankylosing Spondylitis. J Clin Lab Anal.201: 21.

74. Celikbilek M, Dogan S, Akyol L, Borekci E, Zararsiz G, Kozan M, Gunaydın I. Neutrophil-Lymphocyte Ratio in Patients with Familial Mediterranean Fever. J Clin Lab Anal. 2015; 29:80-83.

\section{Tables}


Table 1. Demographic, laboratory and anthropometric parameters of participants by sex 


\begin{tabular}{|c|c|c|c|c|}
\hline \multirow[t]{2}{*}{ Variable } & Total & Male & Female & P-value \\
\hline & Mean (S.D) & Mean (SD) & Mean (SD) & \\
\hline \multicolumn{5}{|l|}{ Demographic parameters } \\
\hline Age (years) & $41.82(8.80)$ & 41.49 (8.62) & $42.36(9.07)$ & 0.02 \\
\hline Education level, N (\%) & & & & $<0.001$ \\
\hline Diploma and lower & $754(27.5)$ & $476(45.4)$ & $278(16.4)$ & \\
\hline Associate & $299(10.9)$ & 121 & 178 (10.5) & \\
\hline Bachelor & $995(36.3)$ & $245(23.4)$ & $750(44.2)$ & \\
\hline Master and Doctorate & $696(25.4)$ & 207 (19.7) & 489 (28.8) & \\
\hline \multicolumn{5}{|l|}{ Laboratory parameters } \\
\hline Uric acid (mg/dl) & $4.80(1.21)$ & $4.81(1.28)$ & $4.76(1.19)$ & 0.42 \\
\hline TG (mg/dl) & $128.07(87.11)$ & $126.61(83.54)$ & $132.56(97.13)$ & 0.16 \\
\hline Total cholesterol (mg/dl) & $180.55(38.74)$ & $184.28(38.45)$ & $169.27(37.46)$ & $<0.001$ \\
\hline HDL-c (mg/dl) & 47.31 (8.99) & 47.19 (8.96) & 47.69 (9.03) & 0.25 \\
\hline LDL-c (mg/dl) & $100.43(25.82)$ & $102.45(27.11)$ & $94.23(20.22)$ & $<0.001$ \\
\hline Neutrophil, $\times 10^{9} / \mathrm{L}$ & $57.10(7.72)$ & $57.03(7.89)$ & $57.22(7.41)$ & 0.60 \\
\hline Lymphocyte, $\times 10^{9} / \mathrm{L}$ & $35.30(7.41)$ & $35.46(7.60)$ & $35.04(7.08)$ & 0.22 \\
\hline NLR & $1.74(0.66)$ & $0.68(0.01)$ & $0.63(0.02)$ & 0.58 \\
\hline Platelet, $\times 10^{9} / \mathrm{L}$ & $261.59(61.62)$ & $264.68(62.15)$ & $256.38(60.40)$ & 0.004 \\
\hline PLR & $7.88(2.69)$ & $7.97(2.72)$ & $7.74(2.64)$ & 0.14 \\
\hline HCT (\%) & $42.12(4.40)$ & $41.81(4.31)$ & $42.65(4.51)$ & $<0.001$ \\
\hline $\operatorname{RBC}\left(10^{6} / \mathrm{mm}^{3}\right)$ & $5.03(0.56)$ & $5.00(0.55)$ & $5.07(0.56)$ & 0.004 \\
\hline $\mathrm{Cr}(\mathrm{mg} / \mathrm{dl})$ & $0.98(0.18)$ & $0.98(0.17)$ & $0.96(0.17)$ & 0.10 \\
\hline \multicolumn{5}{|c|}{ Anthropometric parameters } \\
\hline Weight (kg) & 71.29 (18.69) & $71.47(17.30)$ & $71.01(20.74)$ & 0.53 \\
\hline
\end{tabular}




\begin{tabular}{|c|c|c|c|c|}
\hline Height (cm) & 159.33 (28.85) & $160.43(25.36)$ & $157.51(33.70)$ & 0.01 \\
\hline BMI $(\mathrm{kg} / \mathrm{m} 2)$ & $27.03(4.33)$ & $27.06(4.38)$ & $26.97(4.21)$ & 0.63 \\
\hline BMI categorize, $\mathrm{N}(\%)$ & & & & 0.44 \\
\hline$<18.5$ & $19(0.70)$ & $14(0.80)$ & $5(0.50)$ & \\
\hline $18.5-24.9$ & $881(31.4)$ & $565(32.0)$ & $320(30.3)$ & \\
\hline $25-29.9$ & $1269(45.2)$ & $790(45.1)$ & $479(45.3)$ & \\
\hline$>=30$ & $640(22.8)$ & $387(22.1)$ & $253(23.9)$ & \\
\hline WC (cm) & 89.85 (18.93) & $90.28(17.16)$ & $89.15(21.49)$ & 0.13 \\
\hline WHtR & $0.56(0.06)$ & $0.06(0.001)$ & $0.07(0.002)$ & 0.16 \\
\hline $\mathrm{HC}(\mathrm{cm})$ & 99.64 (18.73) & $100.36(16.63)$ & $98.48(21.67)$ & 0.01 \\
\hline $\mathrm{W} / \mathrm{H}$ & $1.45(0.09)$ & $0.92(0.06)$ & $2.63(1.71)$ & 0.31 \\
\hline $\mathrm{NC}(\mathrm{cm})$ & $35.03(7.14)$ & $35.20(6.41)$ & $34.75(8.18)$ & 0.12 \\
\hline $\mathrm{AC}(\mathrm{cm})$ & $29.24(6.06)$ & $29.42(5.74)$ & $28.95(6.91)$ & 0.06 \\
\hline Wrist circumference (cm) & $37.70(16.22)$ & $16.29(2.79)$ & $16.10(3.61)$ & 0.12 \\
\hline PBF & $33.72(7.86)$ & $33.83(7.92)$ & $33.47(7.74)$ & 0.3 \\
\hline BMR (kcal) & 1407.19 (227.109) & $1406.28(220.20)$ & $1409.21(241.921)$ & 0.77 \\
\hline skinfold fat thickness(mm) & $29.17(10.24)$ & $29.77(9.99)$ & $28.18(10.57)$ & $<0.001$ \\
\hline VFL & $111.52(49.39)$ & $111.03(49.90)$ & $112.34(48.55)$ & 0.50 \\
\hline
\end{tabular}

The mean of uric acid for all subjects was $4.80 \pm 1.21$ and this mean between under and upper median age groups, male and female groups and also among education categories did not show any significant differences, while the mean among BMI levels showed some differences. Consequently, uric acid was increased by BMI increasing (P-value $<0.001)$.

In table 2, the relation between uric acid level and laboratory as well as anthropometric parameters, were evaluated. Most of parameters showed significant relation (all P-value <0.05) except PLR, Cr, VFA and BFM.

Table 2. Relation between uric acid level and laboratory \& anthropometric parameters 


\begin{tabular}{|c|c|c|}
\hline Variable & Correlation & $\mathrm{P}$-value \\
\hline \multicolumn{3}{|l|}{ Laboratory parameters } \\
\hline TG (mg/dl) & 0.43 & $<0.001$ \\
\hline $\mathrm{TC}(\mathrm{mg} / \mathrm{dl})$ & 0.16 & $<0.001$ \\
\hline HDL-C (mg/dl) & -0.26 & $<0.001$ \\
\hline LDL-C (mg/dl) & 0.14 & $<0.001$ \\
\hline Neutrophil, $\times 10^{9} / \mathrm{L}$ & -0.14 & $<0.001$ \\
\hline Lymphocyte, $\times 10^{9} / \mathrm{L}$ & 0.12 & $<0.001$ \\
\hline NLR & -0.13 & $<0.001$ \\
\hline Platelet, $\times 10^{9} / \mathrm{L}$ & 0.06 & 0.03 \\
\hline PLR & -0.04 & 0.14 \\
\hline HCT & 0.45 & $<0.001$ \\
\hline $\mathrm{RBC}\left(10^{6} / \mathrm{mm}^{3}\right)$ & -0.10 & $<0.001$ \\
\hline $\mathrm{Cr}(\mathrm{mg} / \mathrm{dl})$ & -0.005 & 0.82 \\
\hline Anthropometric parameters & & \\
\hline Weight $(\mathrm{kg})$ & 0.37 & $<0.001$ \\
\hline Height (cm) & 0.34 & $<0.001$ \\
\hline BMI $(\mathrm{kg} / \mathrm{m} 2)$ & 0.24 & $<0.001$ \\
\hline WC (cm) & 0.39 & $<0.001$ \\
\hline WHtR & 0.18 & $<0.001$ \\
\hline $\mathrm{HC}(\mathrm{cm})$ & 0.22 & $<0.001$ \\
\hline $\mathrm{W} / \mathrm{H}$ & 0.27 & $<0.001$ \\
\hline $\mathrm{NC}(\mathrm{cm})$ & 0.45 & $<0.001$ \\
\hline $\mathrm{AC}(\mathrm{cm})$ & 0.36 & $<0.001$ \\
\hline Wrist Circumference (cm) & 0.38 & $<0.001$ \\
\hline PBF & -0.18 & $<0.001$ \\
\hline
\end{tabular}

Page $17 / 20$ 


\begin{tabular}{|lcc|} 
BMR (kcal) & 0.43 & $<0.001$ \\
skinfold fat thickness (mm) & 0.15 & $<0.001$ \\
VFL & -0.02 & 0.36 \\
BFM & -0.01 & 0.39 \\
\hline
\end{tabular}

Continuously, relation between uric acid and laboratory and anthropometric parameters according to sublevels of demographic and BMI variables are shown in details in table 3 and 4.

Table 3. Relation between uric acid and laboratory parameters by sex, age, education and BMI levels

\begin{tabular}{|c|c|c|c|c|c|c|c|c|c|c|}
\hline \multirow[b]{2}{*}{$\begin{array}{l}\text { Laboratory } \\
\text { parameters }\end{array}$} & \multicolumn{2}{|l|}{ Sex } & \multicolumn{2}{|l|}{ Age } & \multicolumn{2}{|l|}{ Education } & \multicolumn{4}{|l|}{ BMI } \\
\hline & Female & Male & $\begin{array}{l}\text { Under } \\
\text { median }\end{array}$ & $\begin{array}{l}\text { Upper } \\
\text { median }\end{array}$ & $\begin{array}{l}\text { Non- } \\
\text { collegiate }\end{array}$ & Collegiate & $<18.5$ & $\begin{array}{l}18.5- \\
24.9\end{array}$ & 20- 29.9 & $>=30$ \\
\hline Triglyceride(mg/dl) & $0.43^{*}$ & $0.42^{*}$ & $0.41 *$ & $0.45^{*}$ & $0.42 *$ & $0.43^{*}$ & $0.34^{* * *}$ & $0.36^{*}$ & $0.42 *$ & $0.34^{*}$ \\
\hline Cholesterol(mg/dl) & $0.16^{*}$ & $0.13^{* *}$ & $0.17 *$ & $0.15^{*}$ & $0.11^{* * *}$ & $0.17 *$ & $0.51 * *$ & $0.15^{*}$ & $0.17 *$ & $0.07 * * *$ \\
\hline $\mathrm{HDL}(\mathrm{mg} / \mathrm{dl})$ & $-0.27 *$ & $-0.24^{*}$ & $-0.24 *$ & $-0.29 *$ & $-0.29 *$ & $-0.25 *$ & $-0.59 * *$ & $-0.25 *$ & $-0.25 *$ & $-0.16^{*}$ \\
\hline $\mathrm{LDL}(\mathrm{mg} / \mathrm{dl})$ & $0.12 *$ & $0.17 *$ & $0.15^{*}$ & $0.12 *$ & $0.12^{* *}$ & $0.14^{*}$ & $0.45^{* * *}$ & $0.19 *$ & $0.13^{*}$ & $-0.02 * * *$ \\
\hline Neutrophil× $109 / \mathrm{L}$ & $-0.17 *$ & $-0.06 * * *$ & $-0.11 *$ & $-0.17 *$ & $-0.08 * * *$ & $-0.13^{*}$ & $0.12^{* * *}$ & -0.06 & $-0.14^{*}$ & $-0.19 *$ \\
\hline Lymphocyte×109/L & $0.15^{*}$ & $0.04^{* * *}$ & $0.09 * *$ & $0.15^{*}$ & $0.09 * * *$ & $0.10^{*}$ & $-0.25^{* * *}$ & 0.04 & $0.125^{*}$ & $0.17 *$ \\
\hline NLR & $-.16^{*}$ & $-0.04 * * *$ & $-0.10^{* *}$ & $-0.16^{*}$ & $-0.08 * * *$ & $-0.11 *$ & $019 * * *$ & -0.05 & $-0.13^{*}$ & $-0.18^{*}$ \\
\hline Platelet×109/L & $0.06^{* *}$ & $0.034^{* * *}$ & $0.01^{* * *}$ & $0.09 * *$ & $0.04^{* * *}$ & $-0.02 * * *$ & $-.19 * * *$ & 0.01 & $0.08^{* * *}$ & $0.04^{* * *}$ \\
\hline PLR & $-0.05^{* * *}$ & $-0.004^{* * *}$ & $-0.03^{* * *}$ & $-0.06^{* * *}$ & $-0.01 * * *$ & $-0.05^{* * *}$ & $0.08^{* * *}$ & -0.06 & $-0.02 * * *$ & $-0.07 * * *$ \\
\hline HCT & $0.45^{*}$ & $0.43^{*}$ & $0.45^{*}$ & $0.44^{*}$ & $0.43^{*}$ & $0.45^{*}$ & $0.39 * * *$ & $0.42 *$ & $0.45^{*}$ & $0.42 *$ \\
\hline $\mathrm{RBC}(106 / \mathrm{mm} 3)$ & $-0.11 *$ & $-0.08 * * *$ & $-0.12 *$ & $-0.08 * *$ & $-0.13^{* *}$ & $-0.08 * *$ & $0.22^{* * *}$ & -0.03 & $-0.09 * * *$ & $-0.05^{* * *}$ \\
\hline $\mathrm{Cr}(\mathrm{mg} / \mathrm{dl})$ & $-0.01 * * *$ & $0.03 * * *$ & $-0.008 * * *$ & $0.00 * * *$ & $0.05^{* * *}$ & $-0.02 * * *$ & - & 0.06 & $-0.02 * * *$ & $0.01^{* * *}$ \\
\hline
\end{tabular}


Table 4. Relation between uric acid and anthropometric parameters by sex, age, education and BMI levels

\begin{tabular}{|c|c|c|c|c|c|c|c|c|c|c|}
\hline \multirow[b]{2}{*}{ ic } & \multicolumn{2}{|l|}{ Sex } & \multicolumn{2}{|l|}{ Age } & \multicolumn{2}{|l|}{ Education } & \multicolumn{4}{|l|}{ BMI } \\
\hline & Female & Male & Under & Upper & $\begin{array}{l}\text { Non- collegiate } \\
\text { diploma }\end{array}$ & Collegiate & $<18.5$ & $\begin{array}{l}18.5- \\
24.9\end{array}$ & 20- 29.9 & $>=30$ \\
\hline & $0.35 *$ & $0.47 *$ & $0.37 *$ & $0.38^{*}$ & $0.39 *$ & $0.36^{*}$ & $0.27^{* * *}$ & $0.26 *$ & $0.34^{*}$ & $0.37 *$ \\
\hline & $0.31 *$ & $0.37 *$ & $0.34^{*}$ & $0.33 *$ & $0.34 *$ & $0.31 *$ & $0.26^{* * *}$ & $0.25 *$ & $0.35^{*}$ & $0.38 *$ \\
\hline & $0.24 *$ & $0.32 *$ & $0.23^{*}$ & $0.24 *$ & $0.24 *$ & $0.22 *$ & - & - & $0.06^{* * *}$ & $0.07^{* * *}$ \\
\hline & $0.29 *$ & $0.41 *$ & $0.33^{*}$ & $0.30 *$ & $0.31 *$ & $0.30 *$ & $0.36^{* * *}$ & $0.19 *$ & $0.27 *$ & $0.19 *$ \\
\hline & $0.16^{*}$ & $0.24 *$ & $0.19 *$ & $0.16^{*}$ & $0.16^{*}$ & $0.16^{*}$ & $0.19^{* * *}$ & $0.03^{* * *}$ & $-0.001 * * *$ & $-0.10^{* *}$ \\
\hline & $0.19 *$ & $0.30 *$ & $0.22 *$ & $0.22 *$ & $0.22 *$ & $0.20 *$ & $0.02^{* * *}$ & $0.07^{* *}$ & $0.04^{* * *}$ & $0.04^{* * *}$ \\
\hline & $0.25 *$ & $0.34^{*}$ & $0.26^{*}$ & $0.28^{*}$ & $0.27 *$ & $0.47^{*}$ & $0.25^{* * *}$ & $0.15^{*}$ & $0.14^{*}$ & $0.26^{*}$ \\
\hline & $0.41 *$ & $0.57 *$ & $0.44^{*}$ & $0.45^{*}$ & $0.47^{*}$ & $0.43^{*}$ & $0.32^{* * *}$ & $0.29 *$ & $0.43^{*}$ & $0.44^{*}$ \\
\hline & $0.33^{*}$ & $0.47^{*}$ & $0.36^{*}$ & $0.37 *$ & $0.38^{*}$ & $0.35^{*}$ & $0.41^{* * *}$ & $0.26^{*}$ & $0.29 *$ & $0.34^{*}$ \\
\hline \multirow[t]{4}{*}{ fference } & $0.35^{*}$ & $0.48^{*}$ & & $0.38 *$ & $0.41 *$ & $0.36^{*}$ & $0.28^{* * *}$ & $0.24 *$ & $0.35 *$ & $0.33^{*}$ \\
\hline & $0.41 *$ & $0.52 *$ & $0.43^{*}$ & $0.45^{*}$ & $0.47^{*}$ & $0.59 *$ & $0.007^{* * *}$ & $0.31 *$ & $0.41 *$ & $0.42 *$ \\
\hline & $-0.16^{*}$ & $-0.23 *$ & $-0.17 *$ & $-0.18 *$ & $-0.19 *$ & $-0.17 *$ & $0.16^{* * *}$ & $-0.24^{*}$ & $-0.37 *$ & $-0.30 *$ \\
\hline & $0.41 *$ & $0.49 *$ & $0.42^{*}$ & $0.44^{*}$ & $0.45^{*}$ & $0.41 *$ & $-0.06^{* * *}$ & $0.30 *$ & $0.41 *$ & $0.42 *$ \\
\hline \multirow[t]{3}{*}{ hickness } & $0.14^{*}$ & $0.18^{*}$ & $0.16^{*}$ & $0.14^{*}$ & $0.16^{*}$ & $0.17^{*}$ & $-0.58^{* *}$ & 0.19* & $0.24^{*}$ & $0.17^{*}$ \\
\hline & $0.03^{* * *}$ & $-0.04^{* * *}$ & $-0.02 * * *$ & $-0.01^{* * *}$ & $-0.04^{* * *}$ & $-0.01^{* * *}$ & $-0.05^{* * *}$ & $-0.06^{* * *}$ & $0.02^{* * *}$ & $-0.02 * * *$ \\
\hline & $0.04^{* * *}$ & $-0.05^{* *}$ & $-0.02 * * *$ & $-.0 .01^{* * *}$ & $-0.03^{* * *}$ & -0.02 & $-0.04^{* * *}$ & $-0.06 * * *$ & $0.02^{* * *}$ & $-0.02^{* * *}$ \\
\hline
\end{tabular}

*S P-value $<0.001$

**Significant P-value: $0.001-<0.05$

***Non-profit significant 
The factors related with uric acid using regression model, are shown as table 5 . With the aid of backward method, through 9 steps, the best model with adjusted R square of 0.4 , revealed that Triglyceride, LDL, HDL, Neutrophil, Lymphocyte, platelet, HCT, BMR and skinfold fat thickness, were factors related with uric acid (all p- values $<0.05)$.

Table 5. Results of linear regression model

\begin{tabular}{|l|l|l|l|}
\hline Variable & Beta & $95 \%$ CI & P-value \\
\hline TG (mg/dl) & 0.004 & $(0.003,0.005)$ & $<0.001$ \\
HDL-C (mg/dl) & -0.011 & $(-0.018,-0.003)$ & 0.008 \\
LDL-C (mg/dl) & 0.004 & $(0.001,0.006)$ & 0.006 \\
Neutrophil, $\times 10^{9} / \mathrm{L}$ & -0.028 & $(-0.53,-0.003)$ & 0.030 \\
Platelet, $\times 10^{9} / \mathrm{L}$ & 0.029 & $(-0.055,-0.003)$ & 0.032 \\
HCT (\%) & 0.001 & $(0.000,0.002)$ & 0.018 \\
BMR & 0.077 & $(0.059,0.095)$ & $<0.001$ \\
\hline skinfold fat thickness (mm) & -0.008 & $(-0.016,-0.001)$ & 0.024 \\
\hline
\end{tabular}

